(2) Open Access Full Text Article

\title{
Causes and consequences of injuries in children in Western Australia
}

\author{
This article was published in the following Dove Press journal: \\ Risk Management and Healthcare Policy \\ 6 September 201 I \\ Number of times this article has been viewed
}

\author{
Mallik V Angalakuditi' \\ Nupur Angalakuditi ${ }^{2}$ \\ 'Georgia State University, Atlanta, \\ Georgia, ${ }^{2} \mathrm{New}$ York Medical College, \\ Valhalla, New York, USA
}

Objective: To identify the common causes and consequences of pediatric injury-related admission to an Australian children's hospital.

Methods: A retrospective study was conducted at a pediatric teaching hospital. Patients $<18$ years of age hospitalized between March 1, 2007 and April 30, 2007 were included. Patient medical records were reviewed if an admission diagnosis was injury related. Data collected included date of birth, gender, date of admission, date of discharge, diagnosis, procedure, and causes and outcomes of the injury.

Results: A total of 184 patients were admitted as a result of injury during the study period. Of these, one neonate, six infants, 38 toddlers, 111 children, and 28 teenagers were included in this study. The most common cause of injury-related hospital admission was a fall $(n=109,59 \%)$. Other causes of injury included crushing $(8 \%, \mathrm{n}=15)$, the spilling of fluids $(5.4 \%, \mathrm{n}=10)$, and bites $(4.3 \%, \mathrm{n}=8)$. The most common consequence of an injury for children $(43 / 111,38.7 \%)$ and teenagers $(12 / 28,43 \%)$ was bone fracture. However, head injuries were the most common injury in toddlers $(11 / 38,29 \%)$, infants $(5 / 6,83.3 \%)$, and neonates $(1 / 1,100 \%)$. The radius and/ or ulna $(36 / 63,57 \%)$ were the most common bones fractured. The majority $(32 / 37,86.5 \%)$ of patients who suffered head injuries were diagnosed as having a minor injury.

Conclusion: The main cause of injury-related admission to the hospital for children was a fall, with the most common consequences being fractures and head injuries.

Keywords: injury, falls, head injuries, fractures

\section{Introduction}

Childhood injuries are a major source of morbidity and mortality in Australia, United States, and Canada. In Australia, approximately 300 children are killed and 60,000 hospitalized by injuries each year. ${ }^{1}$ Approximately one out of every 100 Canadian children is hospitalized each year as a result of injuries. In the United States, an estimated 600,000 children are hospitalized every year and more than 15 million children are seen in emergency departments as a result of their injuries. ${ }^{2}$ According to the World Health Organization in 2002, there were over 700,000 deaths in children due to injury. ${ }^{3}$

Injury is a significant cause of death and hospitalization in Australia. In 2004-2005, injuries accounted for 9775 deaths, or $7.5 \%$ of all deaths, and were responsible for $16 \%$ of all hospitalizations in young adults. ${ }^{1}$ In Western Australia, injury is one of the leading causes of hospitalization (2058 per 100,000) and accounts for 28.4 deaths per 100,000 in young adults less than 24 years of age. ${ }^{2}$
Correspondence: Mallik V Angalakuditi Global Health Outcomes and Market Access, Georgia State University, Atlanta, GA, USA

Tel +l 20I 6558662

Email hydmallik02@hotmail.com 
Injury makes a considerable contribution to a child's short- and long-term morbidity, while the fear of injury to their children is one of many contributors to anxiety in parents. ${ }^{4}$ In order to develop programs for reducing injuries in children, it is necessary to identify the common causes and consequences of these injuries. Intervention programs developed and implemented in one region to reduce injuries may not work in another due to cultural, social, economic, and other issues.

Studies identifying the causes and consequences of injuries in children in specific geographic regions are limited. These types of studies are necessary for developing economically sustainable and effective intervention strategies and to reduce unintentional injuries in children. Therefore, the purpose of this study was to identify the common causes and consequences of injury-related admissions in children at a pediatric teaching hospital in Western Australia.

\section{Methods}

A retrospective, descriptive study was conducted at a pediatric teaching hospital of patients less than 18 years of age who were hospitalized between March 1, 2007 and April 30, 2007. This hospital is the only hospital specializing in pediatrics in Western Australia and treats around 300,000 children annually. This study captured the majority of children who were hospitalized due to injuries in Western Australia during the study period. However, some children might have received treatment at a nonpediatric hospital. The hospital has a medical record data repository that houses clinical and financial information for the hospital.

A list of all patients admitted to the hospital during the study period was obtained from the Clinical Coding Department. Medical records were obtained from the Patient Information and Management Services Department, and each record was reviewed manually. If the patient's admission diagnosis during the study period was injury related, then the record was reviewed in detail. If available, the following patient data were collected from the medical records: date of birth, gender, date of admission, date of discharge, and clinical details such as principal diagnosis, other diagnoses, principal procedure, other procedures, causes of injury, outcomes of the injury, and the pathology report. The collected data were analyzed using SPSS Statistics (IBM Corporation, Somers, NY) software and Microsoft Excel ${ }^{\circledR}$ (Microsoft Corporation, Redmond, WA) software.

Patients were categorized into five groups based on age: neonates ( $<30$ days), infants ( 30 days to 12 months), toddlers (1-2 years), children (3-12 years), and teenagers
(13-17 years). Although teenagers are classified as adults in hospitals in other countries, they are treated as pediatric patients in Western Australia.

As this study involved an analysis of patient data, ethical issues arose in relation to confidentiality and release of data. A unique nonpatient identifiable code was allocated to each medical record to enable re-identification if necessary. The data code was kept secure by the Chief Pharmacist of the hospital. The collected data were kept secure in accordance with National Health and Medical Research Council guidelines. ${ }^{5}$ This study was approved by the Human Research Ethics Committee of Curtin University of Technology, Perth, Australia.

\section{Results}

There were 2013 patients aged $\leq 18$ years admitted to the hospital during the study period. Of these, 184 patients were admitted as a result of injury, and $9 \%$ of total admissions were due to injuries in children. There was a total of one neonate, six infants, 38 toddlers, 111 children, and 28 teenagers in this study (Table 1). There were more males than females $(60.3 \%$ versus $39.7 \%)$ in the study population. The main cause of injury-related hospital admissions was a fall $(109,59 \%)$. The second most common cause of injury was as a result of another person $(n=19,10.1 \%)$. Other causes of injury included cuts or crushing in $15(8 \%)$ patients, spilling fluids in $10(5.4 \%)$ patients, and bites in 8 (4.3\%) patients (Figure 1).

The most common consequence of accidents in children $(43 / 111,38.7 \%)$ and teenagers $(12 / 28,43 \%)$ was bone fracture. However, head injuries were the most common consequence of injury in toddlers $(11 / 38,29 \%)$, infants $(5 / 6$, $83.3 \%)$, and neonates $(1 / 1,100 \%)$. Of all the injury-related consequences reported, fractures occurred in 63 (34\%) patients, head injuries in $37(20 \%)$ patients, lacerations/

Table I Causes of injury in various age groups

\begin{tabular}{llll}
\hline Group (age) & $\begin{array}{l}\text { Falls } \\
\text { (\% of total } \\
\text { falls) }\end{array}$ & $\begin{array}{l}\text { Other } \\
\text { (\% of total } \\
\text { other) }\end{array}$ & $\begin{array}{l}\text { Total population } \\
\text { (\% of total } \\
\text { population) }\end{array}$ \\
\hline $\begin{array}{l}\text { Neonates } \\
(<30 \text { days })\end{array}$ & I (0.9\%) & I $(0.5 \%)$ \\
$\begin{array}{l}\text { Infants } \\
(30 \text { days-I year) }\end{array}$ & $4(3.7 \%)$ & $2(2.7 \%)$ & $6(3.3 \%)$ \\
$\begin{array}{l}\text { Toddlers } \\
(I-2 \text { years })\end{array}$ & $2 I(19.3 \%)$ & $17(22.7 \%)$ & $38(20.7 \%)$ \\
$\begin{array}{l}\text { Children } \\
(3-12 \text { years })\end{array}$ & $68(62.4 \%)$ & $43(57.3 \%)$ & $111(60.3 \%)$ \\
$\begin{array}{l}\text { Teenagers } \\
(I 3-17 \text { years) }\end{array}$ & $15(13.8 \%)$ & $13(17.3 \%)$ & $28(15.2 \%)$ \\
\begin{tabular}{l} 
Total \\
\hline
\end{tabular} & $109(59.2 \%)$ & $75(40.8 \%)$ & 184 \\
\hline
\end{tabular}




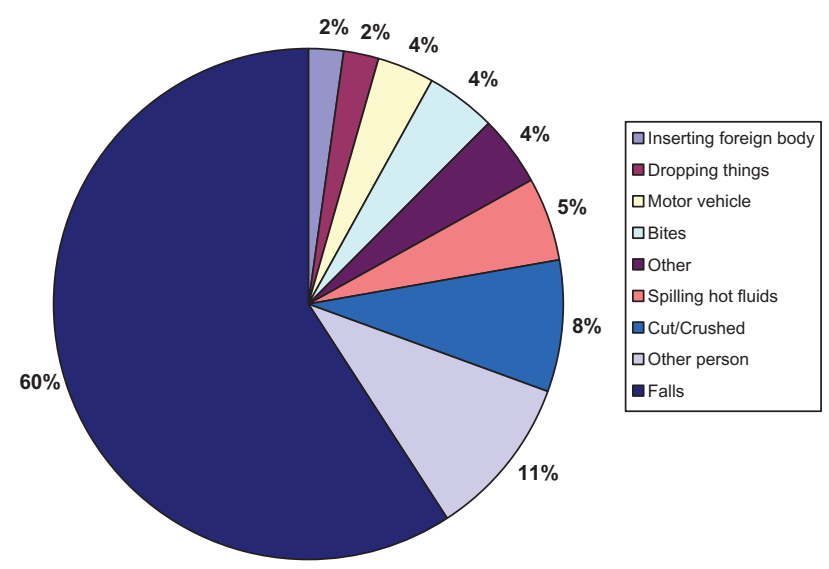

Figure I Causes of injuries in children.

abrasions in $33(17.9 \%)$ patients, 15 were crushed ( $8 \%)$, and 12 were burned $(6.5 \%)$. Other consequences were reported in $24(13 \%)$ patients.

The radius and ulna $(36 / 63,57 \%)$ were the most common bones fractured. Other bones fractured included the supra condyle $(8 / 63,12.6 \%)$, humerus $(5 / 63,7.9 \%)$, and tarsal/ phalanges $(4 / 63,6.3 \%)$. Other, miscellaneous bones were fractured in $10(15.8 \%)$ patients. Of the 37 patients who suffered head injuries, $32(86.5 \%)$ patients were diagnosed with minor injuries, four $(10.8 \%)$ had major injuries, and one patient $(2.7 \%)$ had a brain hematoma.

Most patients fell from a chair $(n=26,23.8 \%)$. Other patient activities which brought about falls included bike riding $(\mathrm{n}=18,16.5 \%)$, playing $(\mathrm{n}=15,13.7 \%)$, losing balance $(\mathrm{n}=11,10 \%)$, and falling from a tree $(\mathrm{n}=7,5.5 \%)$. Data concerning the causes of fall-related injuries are presented in Figure 2.

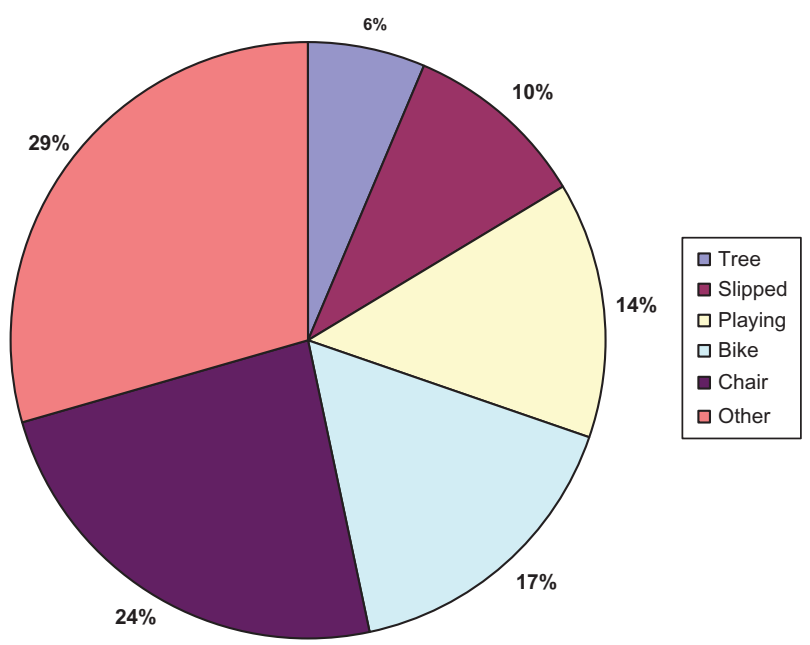

Figure 2 Causes of fall-related injury.
Twelve $(6.5 \%)$ patients were admitted due to burn-related injuries. In three (25\%) patients, burns were the result of the spilling of hot drinks or hot food; four (33\%) patients were burned by hot water; and two (16.6\%) were burned by an electrical current. Among the 12 burn patients, four were toddlers, seven were children, and one was a teenager.

Of the nine patients admitted because of bites, seven were due to dog bites, one was due to a snake bite, and one due to a spider bite. Four patients were admitted for foreign body insertion-related injuries. Of these, three patients inserted a foreign body into the mouth and the other into the orifice of the ear.

Most injuries occurred at the patients' home (92, 50\%). Other common settings of injury were the road $(\mathrm{n}=32$, $17 \%)$, a park or garden $(n=22,12 \%)$, school $(n=15,8 \%)$, or swimming pool $(n=5,2.7 \%)$. Injury locale data are summarized in Figure 3.

\section{Discussion}

This study describes the causes and consequences of injuryrelated admissions among various age groups in a pediatric teaching hospital in Western Australia. The authors found that the main cause of injury-related admission to the hospital in children was due to falls, and the most common consequences were fractures and head injuries. The bones fractured most frequently were the radius and ulna.

According to this study and Australian National Injury data findings, most children are injured in the home. Other common locations included automobiles, parks, and school grounds. Parent supervision is a powerful factor in preventing injury. Continuing education on safety for parents, careworkers, and children should be emphasized. Parents and caretakers should be educated on the importance of instructing children on safety issues at home and school, as well as the proper supervision and modeling that they should

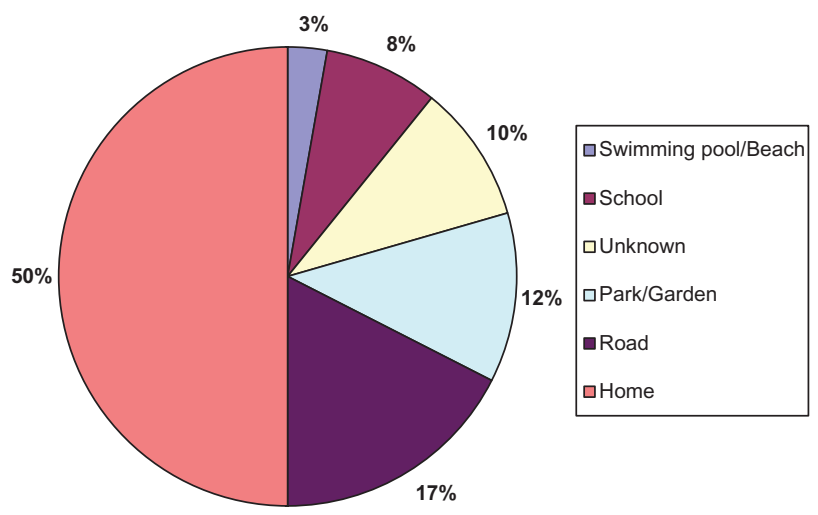

Figure 3 Where injuries occur. 
provide for children under their care. ${ }^{6}$ Children are safer playing in a public playground than on the road. Modernizing playgrounds may reduce head injuries, lacerations, and abrasions and certainly should provide good play opportunities for children. It is essential to create and maintain safer playgrounds in which children can develop their skills and play with a minimal risk of injury. ${ }^{7}$

In Australia, the prevention of falls has been a national health priority. ${ }^{9}$ During 1979-1998, falls ranked sixth as a cause of injury-related death and accounted for 20,193 deaths due to accidental falls of all ages. ${ }^{9}$ Also during this period, there were 25,590 episodes of hospital care required for children $<15$ years old and $9 \%$ of these episodes were accidental. ${ }^{9}$ Falls are a major public health issue in Western Australia and accounted for around 1300 hospitalizations per 100,000 people from 1979 to $1998 .{ }^{9}$ As such, this creates a huge burden on the Western Australian heath care system. Fall-related deaths are few in number in the pediatric population, but result in emotional suffering nonetheless. Yet falls account for $40 \%$ of hospital admissions due to injury, making them the leading cause of hospitalization among children. ${ }^{9}$

Falls were the leading cause of injury-related admission to the hospital in this study, which is in agreement with national findings. It was most common for a child to fall from a chair or bike. Most children suffered bone fractures or head injuries as a result of a fall. The upper limb (commonly radius and ulna), head, and face were the most common body regions injured in a fall. In general, the fall-related injuries occurred most often at a patient's home. With increasing age, the pattern of activity and place of injury occurrence changes with a gradual shift from the home to a place of recreation and sports. ${ }^{8}$ Children frequently sustain fractures and head injuries due to their large heads relative to body size and limited ability to protect themselves during a fall. ${ }^{9}$

Burn-related injuries were the fifth leading cause of hospitalization in this study. Most patients admitted were children less than 5 years of age, which is in line with Australian national trends. In Australia, fires and burns were responsible for 20-25 deaths, 600 hospital admissions, and 6000 emergency room visits in children each year, while in Western Australia alone, fires and burns ranked eighth as a cause of injury-related death and seventh as a cause of injury-related hospitalizations. Such injuries contribute to nine deaths and 791 hospitalizations on average per year in Western Australia. ${ }^{1}$

In this study, four children under the age of 5 years inserted foreign bodies into the mouth or orifice of the ear. Generally, younger children were more likely to insert foreign bodies; perhaps older children are more conscious of the consequences and have a fear of being suffocated. ${ }^{10}$ The continuing education of children and parents to prevent the insertion of foreign bodies into the body orifices and appropriate management of these cases by the otolaryngologist are of principal importance. ${ }^{10}$

Each year more than 100,000 people are attacked by dogs, with children having the highest incidence of receiving such injuries. Sixty percent of all serious bites occur in children $<10$ years old. ${ }^{11}$ Dog attacks can result in people suffering bruises, lacerations, crushing injuries, fractures, and phobias about dogs. When compared with females, males are more likely to be bitten by dogs. ${ }^{12}$ The present study's findings confirm this finding, as all of the patients bitten by a dog were male. Dog bites can be avoided by educating and supervising children, as well as constructing barriers that appropriately separate the dog and the child. Recognizing and managing the anxiety and behavior of the animal may further result in the decline of dog bites.

To implement effective intervention strategies to prevent injury to children, it is necessary to better understand the antecedents of injuries in children and the environments in which they occur. A great deal of data is needed to implement and maintain effective intervention in child injury prevention, which can only be collected through careful investigation. ${ }^{12}$ Greater resources are needed to implement effective prevention strategies and to ensure that optimal acute care and rehabilitation are available and accessible for those injuries that are not prevented. ${ }^{3}$

In this study, most of the children were injured because they were playing in an unsafe environment. These environments must be identified and modified in order to make play areas safer for children. ${ }^{6}$ Providing a safer environment for children to play is fundamental to preventing injury and would be most effective in reducing injuries among children. In conjunction, preventive strategies such as proper supervision and safety education are necessary. ${ }^{6}$

\section{Implications of prevention}

Risk factors that have been identified as increasing the risk of pediatric injury include poverty, single-parent households, child hyperactivity, and poor mental/physical health. ${ }^{13}$ Previous efforts to prevent injuries have focused on proper safety equipment, injury prevention education, interventions for children, parents, and teachers, and public awareness campaigns. ${ }^{13}$

Specific intervention strategies to address the issues that have been discussed in this paper include providing safer playgrounds, wearing helmets when appropriate, knee and 
elbow protectors, appropriate footwear, proper supervision, and constructing barriers to keep dogs away from small children. These specific prevention strategies should be combined with other efforts such as legislation, parent and caregiver education, and updated federal safety requirements. Together, these efforts should potentially help to reduce the risk of injury in children. Preventing unintentional injuries in children will allow the utilization of health care resources for other purposes.

\section{Conclusion}

This retrospective study was carried out to identify the causes and consequences of injuries in children in Western Australia. The main cause of injury-related hospital admission was due to falls. The most common consequence of injury in children and teenagers was a bone fracture. Head injuries were the most common consequence of injury in toddlers, infants, and neonates. The radius and ulna were the bones most commonly fractured.

\section{Acknowledgments}

The authors would like to thank Bruce Sunderland, Professor, School of Pharmacy, Curtin University of Technology, Perth, Australia, for his help in the data collection and ethics application preparation. Curtin University of Technology School of Pharmacy supported the study.

\section{Disclosure}

The authors have no conflicts of interest to disclose in relation to this paper.

\section{References}

1. Henley G, Harrison JE. Injury Deaths, Australia 2004-05. AIHW injury research and statistics series no 51. Canberra: Australian Institute of Health and Welfare; 2009. Available from: www.aihw.gov.au/WorkArea/ DownloadAsset.aspx?id=6442458853. Accessed August 23, 2011.

2. Lillis KA, Jaffe DM. Playground injuries in children. Pediatr Emerg Care. 1997;13(2):149-153.

3. World Health Organization. Injuries. Available from: http://www.who. int/topics/injuries/. Accessed April 9, 2006.

4. Australian Institute of Health and Welfare. Injury Among Young Australians. AIHW bulletin series no 60. Canberra: Australian Institute of Health and Welfare; 2008. Available from: www.aihw.gov.au/WorkArea/ DownloadAsset.aspx?id=6442452801. Accessed August 23, 2011.

5. Aitken ME, Herrerias CT, Davis R, Bell HS, Combs JB, Ckleinman L. Minor head injury in children. Arch Pediatr Adolesc Med. 1998;152: 1176-1180.

6. NHMRC.gov.au [homepage on the Internet]. Australia: National Health and Medical Research Council. Available from: http://www.nhmrc.gov. au/. Accessed September 10, 2007.

7. Lam LT, Ross FI, Cass D. Children at play: the death and injury pattern in New South Wales, Australia, July 1990-June 1994. J Paediatr Child Health. 1999;35:572-577.

8. Mott A, Evans R, Rolfe K, Potter D, Kemp KW, Sibert JR. Patterns of injuries to children on public playgrounds. Arch Dis Child. 1994;71:328-330.

9. Steenkamp M, Cripps R. Child Injuries Due to Falls. AIHW injury research and statistics series no 7. Canberra: Australian Institute of Health and Welfare; 2001.Available from: www.nisu.flinders.edu.au/ pubs/reports/2001/falls_injcat37.pdf. Accessed August 23, 2011.

10. Young SJ, Barnett PLJ, Oakley EA. Fractures and minor head injuries: minor injuries in children II. Med J Aust. 2005;182:644-648.

11. Balbani APS, Sanchez TG, Butugan O, Kii MA, Angelico FV, Ikino CMY. Ear and nose foreign body removal in children. Int J Pediatr Otorhinolaryngol. 1998;46:37-42.

12. Thompson P. The public health impact of dog attacks in a major Australian city. Med J Aust. 1997;167(3):129-132.

13. Roberts H. Qualitative research methods in interventions in injury. Arch Dis Child. 1997;76(6):487-489.

14. Fallat ME, Costich J, Pollack S. The impact of disparities in pediatric trauma on injury prevention initiatives. $J$ Trauma. 2006;60: 452-454.

\section{Publish your work in this journal}

Risk Management and Healthcare Policy is an international, peerreviewed, open access journal focusing on all aspects of public health, policy, and preventative measures to promote good health and improve morbidity and mortality in the population. The journal welcomes submitted papers covering original research, basic science, clinical \& epidemio-

\section{Dovepress}

logical studies, reviews and evaluations, guidelines, expert opinion and commentary, case reports and extended reports. The manuscript management system is completely online and includes a very quick and fair peerreview system, which is all easy to use. Visit http://www.dovepress.com/ testimonials.php to read real quotes from published authors. 